\title{
Raciborskiella parva Xavier Filho nova espécie de Strigulaceae (Líquens) do Estado do Amazonas
}

\author{
Lauro Xavier Filho $\left(^{(*)}\right.$
}

\begin{abstract}
Resumo
Descrição de Raciborskiella parva Xavier Filho nova espécie da familia Striguiaceae coletada no Estado do Amazonas.
\end{abstract}

\section{INTRODUÇÃO}

Continuando no estudo sistemático da líqueno-flora brasileira, descrevemos neste trabalho uma nova espécie de Strigulaceae, pertencente ao gênero Raciborskiella Höhnel, 1909 , sobre folhas vivas de plantas não identificadas, provenientes da borda do rio Paranauari, Maués-Amazonas e coletado pelos Drs. Omir Fontoura e Amaro Andrade em 6/2/1961, tipo IMUR, n. ${ }^{\circ}$ 21.611. A espécie ora ostudada difere de $R$. janeirensis (Mull. Arg.) R. Sant. e R. prasina (Mull. Arg.) R. Sant., principalmente pelo tamanho dos ascos e ascosporos que são menores e por possuir apenas 1 septo nos ascosporos, enquanto que as espécies citadas acima possuem de 1 a 3 septos.

\section{Raciborskiella parva Xavier Filho n. sp.}

Talo algífero, epífilo, subcuticular, efigurado, arredondado, levemente lobado, monocárpico ou com várias frutificações, geralmente conexo, liso, verde-negro, $1.5-6 \mathrm{~mm}$ de diam., tendo células subglobosas, de $6-10 \mu$ de diam. - Hipotalo ausente. Ascostromas subcuticulares inteiramente recobertos pelo talo algífero, isolados ou agrupados, marrom-negros, conexos, 400-500 $\mu$ de diam.; ostíolo circular, $12-18 \mu$ de diam.; paredes prosopletenquimáticas, negras, 20-27 $\mu$ de diam., diferenciando lóculo peritecígero, 54-70 x 60-70 $\mu$; himênio normal, hialino, simples. Ascos pa- ralelos, cilindro-clavados, 2 tunicados, curtopedicelados, inoperculados, 8-esporos, $38-50 \times$ 5-6 $\mu$; paráfises filiformes, ramificadas e anastomosadas, septadas, 1-1,5 $\mu$ de diam., - Ascosporos fusoides, hialinos, 1-septados pouco constrictos, levemente macrocéfalos, dísticos, lisos, 6-7 $\times 1.5-2 \mu$.

\section{Alga simbionte - Cephaleuros sp.}

Sobre folhas vivas de planta não identificada, associado a Bacidia fusctula (Mull. Arg.) A. Zahlbr., Chlorococcaceae sp., Chroodiscus coccineus (Leight.) Mull. Arg., Trichopeltomyces phillippinensis Batista \& Costa, Porina conica R. Sant., Mazosia dispersa (Hedrick) R. Sant. - rio Paranauari, Maués Amazonas, Legs. Drs. Omir Fontoura \& Amaro Andrade, 6/2/1961 - Tipo 21.611, IMUR.

Thallus algiferus epiphyllus, subcuticularis, effiguratus, rotundatus vel parum lobatus, monocarpus vel polycarpus, convexus, laevigatus, atro-viridens, $1.5-6 \mathrm{~mm}$ de diam., ex cellulis subglobosis, 6-10 $\mu$ diam. effectus; hypothallus non visus. Ascostromata subcuticularia, omnino thalo vestita, sparsa vel aggregata, atro-brunnea, convexa, 400-500 $\mu$

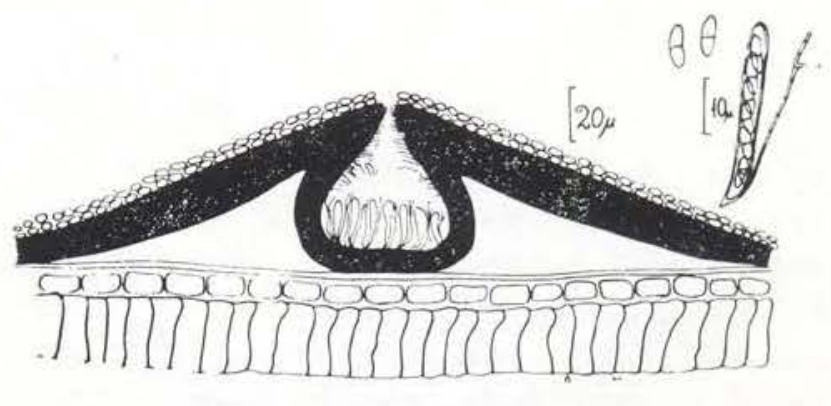

Raciborskiella parva Xavier Filho n. sp.

(") - Instituto de Biociências da Universidade Federal de Pernambuco. 
diam., ostiolo centralı, rotundato, 12-18 $\mu$ diam., paritibus prosoplectenchymaticis, atris, 20-27 $\mu$ cr. camara peritheciali, $54-70 \times 60-70 \mu$ atque hymenio simplici, hyalino praedita. Asci paraleli, cylindro-clavati, 2-tunicati, curto-stipitati, non operculati, 8-spori, 38-50 x 5-6 $\mu$, paraphyses filiformes, ramosas, anastomosantes, septatas, hyalinas, 1-1.5 $\mu \mathrm{cr}$. ostendentes. Ascosporae fusoideae, 1-septatae, parum constrictae, distichae, laevigatae, hyalinae, $6-7 \times 1.5-2 \mu$. Alga ad Cephaleuros $s p$. In foliis vivis plantae ignotae, soc. iniens cum Bacidia fuscatula (Mull. Arg.) A. Zahlbr., Chlorococcaceae sp., Chroodiscos coccineo (Leight.) Mull. Arg., Trichopeltomyces philippinensis Batista \& Costa, Porina conica R. Sant. Mazosia dispersa (Hedrick) R. Sant. - Rio Paranauari, Maués - Amazonas - Legs. Omir Fontoura \& Amaro Andrade, 6/2/1961 - Typus, 21.611, IMUR.

\section{AGRADECIMENTOS}

Agradecemos ao Instituto de Biociências da UFPE., na pessoa do seu Diretor, Dr. Evans de Azevedo e Silva, pelo incentivo e ao Prof. Geraldo Mariz pelas sugestōes e comentários, assim como ao Prof. Fernando de B. Leal pela ajuda na revisão da diagnose latina.

\section{SUMMARY}

A new species of Strigulacea from Amazonas State (Brazil) named Raciborskiella parva Xavier Filho is here described.

\section{BIBLIOGRAFIA CITADA}

SANTESSON, R.

1952 - Foliicolous lichens I. Symbolae Bat., Suecia, 12:1-590. 